\title{
Evaluation of the acute toxicity of a mosquito coil based-meperfluthrin
}

\begin{abstract}
Coils or burning coils are human biting insect repellents (flies, bees, wasps, mosquitos...). These products are widely used to fight against malaria and dengue vectors in tropical countries. The aim of this study was to assess the acute toxicity by oral, dermal, ocular and pulmonary routes of a mosquito coil and its classification in the globally harmonized system of classification and labeling of chemicals (GHS). Various tests were carried ou according to OECD 423 guidelines (2001) for the acute toxicity by oral route, OECD 436 (2009) for the acute toxicity test by inhalation and OECD 402 (1987) and 404 (2015. Signs of toxicity such as apathy and drowsiness were observed at the dose of $2000 \mathrm{mg} / \mathrm{Kg}$ by oral route. Toxicity through inhalation is characterized by a lung disease associated with bronchial and interstitial pneumonia, a tubulointerstitial nephritis with renal impairment and a LC50 (rat) ranging from 5 to $10 \mathrm{mg} / 1 / 4 \mathrm{~h}$. The coil studied was non-irritating by ocular and dermal routes. Results showed a high toxicity of the coil by pulmonary route. The LC50 (rat) between 5 and $10 \mathrm{mg} / 1 /$ suggests a classification in category 3 of the product studied in the Globally Harmonized System of classification and labeling of chemicals (GHS).
\end{abstract}

Keywords: acute toxicity, oral route, dermal, ocular, inhalation, coil, ghs, oecd guidelines
Volume 3 Issue 7 - 2017

\author{
Manda Pierre, 'Abouna Alain Didier, ${ }^{2}$ \\ Adepo Aholia Jean Baptiste,' Dano Djédjé \\ Sébastien' \\ 'Laboratoire de Toxicologie, Université Félix Houphouët Boigny, \\ Côte d'lvoire \\ 'Laboratoired' Anathomopathologique, Université Felix \\ Houphouët Boigny, Côte d'lvoire
}

\begin{abstract}
Correspondence: Manda Pierre, Laboratoire de Toxicologie, UFR Sciences, Pharmaceutiques et Biologiques, Université Félix Houphouët Boigny, 22 bp 21 Abidjan 22, Côte d'lvoire, Tel 00225
\end{abstract} 056987 26, Email mandapierre@yahoo.fr

Received: November 20, 2017 | Published: December 04, 2017

inhalation toxicity tests, the New Zealand breed rabbits for dermal and ocular toxicity test. These animals underwent a minimum of 5 days of acclimation in the animal room at the faculty of Pharmaceutical and Biological Sciences. Animals had free access to water and food. During acclimation, rats were housed in groups of 5 in a polycarbonate cages in the animal room.

\section{Methodology}

Oral toxicity : The experiment was conducted according to OECD 423 guidelines. ${ }^{6}$ The substance was tested in a sequential process in which three animals were used at each stage. Two dose levels were tested: 300 and $2000 \mathrm{mg} / \mathrm{kg}$. In total, 12 rats distributed in 2 groups of 6 animals were treated and observed for 14 days to seek for signs of acute intoxication. Dose administration was performed by oral route (intra-esophageal) at the rate of $1 \mathrm{ml}$ per $100 \mathrm{~g}$ of body weight.

Inhalation toxicity : The study of acute inhalation toxicity was carried out according to OECD 436 guidelines. ${ }^{7}$ Four levels of doses were basically tested with OECD 436 guidelines $^{7}$ for vapors. These are: $0.5-2 \mathrm{mg} / \mathrm{L}-10$ and $20 \mathrm{mg} / 1 / 4 \mathrm{H}$. For each dose, six rats were tested ( 3 females and 3 males). The inhalation chamber was designed for full body exposure. It is a transparent polycarbonate chamber and allows observation of the animal during the experiment. The chamber had the following dimensions: $45 \mathrm{~cm} \times 32 \mathrm{~cm} \times 28 \mathrm{~cm}$. The test substance was burnt to generate vapors in the chamber which was then closed. The exposure period was 4 hours. The absence of death and moribund state among animals in the first Test allowed us to use a higher dose level.

\section{Dermal and ocular toxicity}

It consisted in determining signs of dermal and ocular irritation. The OECD 402 guideline $^{8}$ and $404^{9}$ were used as methodology. For dermal test: 24 hours prior to test, about $5 \mathrm{~cm} \times 5 \mathrm{~cm}$ on both sides of the dorsal part of the rabbit is shorn. $0.5 \mathrm{~g}$ of the coil powder is first applied on a gauze compress and then put on the skin. The compress is kept in soft contact with the skin using a semi occlusive dressing

Experimental animals : OFA rats were used for the acute oral and 
(plaster). The opposite side, which did not receive any treatment, serves as a control. After 4 hours of contact, the dressing is removed and the clinical signs of erythema and edema are investigating using a magnifying glass. This evaluation is renewed 24; 48; and 72 hours after product application. Observations are made on the treated area compared to the control area according to the Draize scale. The illustrated rating manual of dermal lesions of EPA. ${ }^{10}$ Atlas of dermal Lesions was used as a reference for scoring.

For the ocular test: $100 \mathrm{mg}$ of the coil powder were inserted into the conjunctival right eye bag of the rabbit, after discarding the lower eyelid from the eyeball. The other eye, which did not undergo any treatment, served as a control. The eyes were examined 4 hours after product application using a binocular magnifying glass and a lamp. The evaluation was performed according to the control eye. The intensity of ocular reactions (connective, cornea and Iris) was recorded at each examination.

\section{Clinical Signs and histological examinations}

The observations were focused on body weight changes and clinical signs of intoxication for each dose level administration for 14 days. The clinical signs of toxicity sought were: behavioral abnormalities; dermal and mucous membrane abnormalities; Signs indicating partial

Table I Variation of the mean body weight of animals treated by oral route or widespread nerve damage; Signs reflecting a digestive impairment, signs indicating a corrosive and vascular effect and eventual mortality.

A constant observation was made from the first four (4) hours after product administration. A daily observation was carried out from the $2^{\text {nd }}$ to the $14^{\text {th }}$ day. Histological examinations were performed on organs (lung, liver, kidney, heart) of animals exposed to high doses.

\section{Results}

\section{Acute oral toxicity}

The clinical signs of intoxication observed at the dose of $2000 \mathrm{mg} /$ $\mathrm{kg}$ had the following characteristics: apathy, drowsiness, difficulty of locomotion during the first 3 hours. Then, animals recover their normal state. No mortality was recorded during the experiment. A body weight gain ranging from 3.80 to $4.03 \mathrm{~g}$ in treated animals was recorded. Comparison of animal body weights before and after treatment showed no significant difference (Table 1). Examination of the histological sections of renal tissue fragments exhibited a polymorphic inflammatory reaction associated with a vascular congestion and oedema. This is an acute lesion (glomerulonephritis). The other organs (liver, lungs) remained with no particularity. According to the sequential process of OECD 423 guideline, ${ }^{11}$ the LD50 is greater than $2000 \mathrm{mg} / \mathrm{kg}$.

\begin{tabular}{lllll}
\hline \multirow{2}{*}{ Doses administered $\mathbf{m g} / \mathbf{k g}$} & \multicolumn{2}{l}{ Mean body weight of animals $\mathbf{( g )}$} & Variation $\mathbf{( g )}$ & Student's test (5\%) \\
\cline { 2 - 3 } & D & D 14 & $5.1 \pm$ & \\
\hline Control & $195.41 \pm 21$ & $200.51 \pm 18$ & 4.03 & NS \\
300 & $192.6 \pm 23$ & $197.23 \pm 25$ & 3.8 & NS \\
2000 & $203.28 \pm 16$ & $206.08 \pm 20$ & \\
\hline
\end{tabular}

\section{Inhalation toxicity}

Clinical signs of acute toxicity : Clinical signs of intoxication are observed from the dose of $2 \mathrm{mg} / \mathrm{l} / 4 \mathrm{~h}$ and are recorded in Table 2 below. Likewise, the first cases of mortality are recorded in the group exposed to the dose of $20 \mathrm{mg} / 1 / 4 \mathrm{~h}$. This result helps to evaluate the LD50 which is between 10 and $20 \mathrm{mg} / \mathrm{Kg}$.

Table 2 Clinical signs of intoxication

\begin{tabular}{|c|c|c|c|}
\hline \multirow{2}{*}{$\begin{array}{l}\text { Initial } \\
\text { concentration }\end{array}$} & \multirow{2}{*}{ Signs of toxicity } & \multicolumn{2}{|l|}{ Mortality } \\
\hline & & Number & From: (Hours) \\
\hline $0.5 \mathrm{mg} / \mathrm{l} / 4 \mathrm{~h}$ & No clinical signs of intoxication & $0 / 6$ & \\
\hline $2 \mathrm{mg} / \mathrm{l} / 4 \mathrm{~h}$ & $\begin{array}{l}\text { Slight drowsiness towards the end of exposure The animals recovered their initial state I } \\
\text { hour after the end of exposure }\end{array}$ & $0 / 6$ & \\
\hline $10 \mathrm{mg} / / / 4 \mathrm{~h}$ & Drowsiness and marked apathy, the animals recovered their normal state after 24 hours & $0 / 6$ & \\
\hline $20 \mathrm{mg} / / / 4 \mathrm{~h}$ & Drowsiness and marked apathy after 20 minutes of exposure, & $6 / 6 / 2017$ & $\begin{array}{l}\text { From } 2 \text { hours of } \\
\text { exposure }\end{array}$ \\
\hline
\end{tabular}

\section{Results of histological examinations}

Histological sections were performed on the organs (lungs, kidneys and heart) collected from rats after exposure.

In the lungs : Inflammatory abnormalities were observed from the dose of $10 \mathrm{mg} / \mathrm{l} / 4 \mathrm{~h}$ and were exacerbated at the highest dose $(20 \mathrm{mg} /$ $1 / 4 \mathrm{~h}$ ) of the toxicological experiment. Thus, at the dose of $20 \mathrm{mg} / 1 / 4 \mathrm{H}$, a granulomatous inflammatory infiltrate with pneumocytic hyperplasia associated with fibrosis and vascular congestion was observed. There were also hemorrhage areas. All of this exhibits a diffuse interstitial fibrosis.

In the kidney : At a dose of $20 \mathrm{mg} / \mathrm{L} / 24 \mathrm{~h}$, the fragments of renal tissue examined were the site of a vascular congestion associated with vacuolar degeneration. There was also a diffuse lymphoplasmocytic infiltrate indicating a tubulo-interstitial nephritis (Figure 1). 


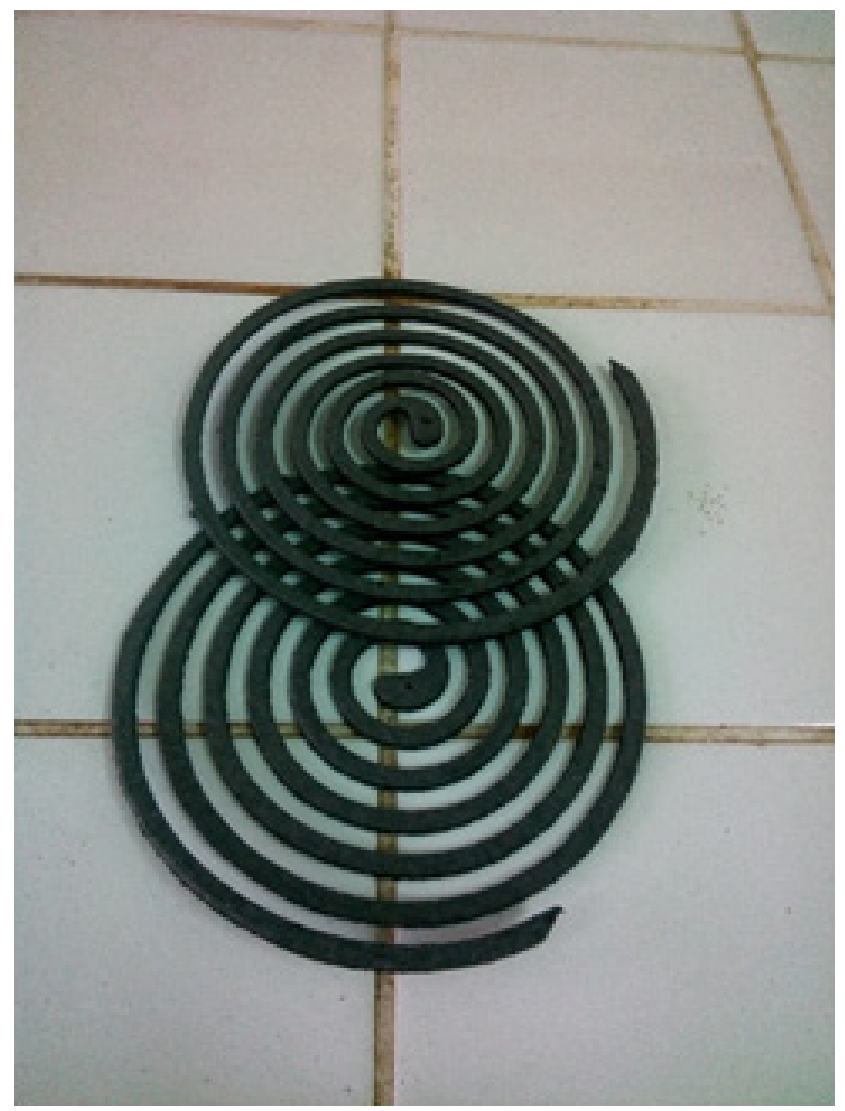

Figure I Mosquito coil.

\section{Dermal and ocular toxicity}

The evaluation of the primary dermal irritation was performed according to Draize scale. No erythema or Eschar or oedema was observed on the treated sides of the three rabbits. In these conditions, the primary dermal irritation indice (I.P) equals to zero. The coil studied belongs to the class of products considered to be non-irritating to the skin (IP $<0.5)$ according to OECD Classification (Table 3 ). The fragments of tissue collected from the side treated with the coil do not show any architectural abnormality of the Malpighian epithelium or inflammatory infiltration. The whole presents the histological aspect of normal Malpighian tissue. The eyes were examined using a binocular magnifying glass and a lamp after 4 hours of product application. The evaluation of ocular irritation was carried out according to the control eye using a binocular magnifying glass and a lamp, the eyes were examined after 4 hours of product administration.

Table 3 Classification table of products according to their indice

\begin{tabular}{ll}
\hline Product classification & Indice \\
\hline Non-irritating & $\mathrm{IP}<0,5$ \\
slightly irritating & $0.5 \leq \mathrm{IP}<2$ \\
Irritating & $2 \leq \mathrm{IP}<5$ \\
very irritating & $5 \leq \mathrm{IP}<8$ \\
\hline
\end{tabular}

No signs of opacity or ulceration were observed in the cornea. No abnormalities were observed in the iris. No conjunctival lesions, chemosis or tearing were observed at the end of the 4-hour exposure. Twenty-four hours after treatment, the eyes recovered their normal state. According to the results, the coil studied can be considered as non-irritating for eyes.

\section{Discussion}

A few years ago, mosquito coils contained active ingredients that were undoubtedly hazardous for humans (eg, DDT). ${ }^{4}$ Today they are mostly made of pyrethrum, a plant based product-or synthetic pyrethroids from the same family. These substances are significantly less hazardous, but not risk-free. The mosquito coil studied contains meperfluthrin as active ingredient, an insecticide from the family of pyrethroids. The toxicity of the entire formulation was evaluated by four routes: oral, ocular, dermal and by inhalation. The experimental study showed a marked toxicity of the coil by inhalation route compared to the other three routes studied. Indeed by oral route, LD50 greater than $2000 \mathrm{mg} / \mathrm{kg}$ allowed a classification in Category 5 according to GHS. As for the dermal and ocular routes, the primary irritation indices determined were all equal to zero, and showed that the coil studied was non-irritating by these two routes. Only the inhalation route revealed the coil toxicity through clinical signs of apathy and drowsiness. This respiratory route had the merit to take into account the user real exposure situation.

Indeed, in real exposure situation, the user is exposed to the entire coil which by burning diffuse the insecticide active ingredients but also the combustion products of the entire product. These signs of intoxication were dose-dependent and more marked at the high dose of $20 \mathrm{mg} / 1 / 4 \mathrm{~h}$. According to the Protocol adopted and the results obtained by the number of deaths and moribund animals, the LC50 was between 5 and $10 \mathrm{mg} / 1 / 4 \mathrm{~h}$ and was classified in category 3 according to GHS. Signs of toxicity observed in the respiratory route were correlated with the histological examinations that revealed bronchial pneumonia in the lungs, acute glomerulonephritis. This toxicity is due to the complex mixture resulting from the smoke of the burning coil. Scientific studies showed that mosquito coils while burning can release hazardous pollutants that may cause health risk. ${ }^{12,13}$ By taking into account these information, the user's exposure, under the conditions of use of 1 coil per day, is low.

In 2010, the Toxicovigilance Coordination Committee, ${ }^{14}$ following the compilation of 117 files from toxicovigilance centers, concluded a low exposure of users to mosquito coils. The signs reported in users were respiratory, eyes and nasal irritation. According to these results, the Committee recommended the use of coils outdoors to reduce health risk. Other authors investigating the exposure to coil smoke, reported an increase risk for lung cancer, an increase in asthma. These authors attributed coils toxicity to a complex mixture of pollutants resulting from its combustion.

\section{Conclusion}

Coils are complementary means to be taken into account in the campaign against mosquito, vector of malaria. For a better control of health risk associated with mosquito coils, it is advisable to: certify all the products on the market evaluate products generated through combustion and encourage the development of coils releasing less Copollutants. 


\section{Acknowledgements}

None.

\section{Conflict of interest}

The author declares no conflict of interest.

\section{References}

1. Doannio JMC, Konan YL, Amalaman K, et al. Connaissances, attitudes et pratiques des populations vis-à-vis des moustiques dans la zone urbaine et périurbaine de Bouaké et dans les villages de Kafiné et de Kabolo (Côte-d'Ivoire, Afrique de l'Ouest). Bull Soc Pathol Exot. 2004;97(4):295-301.

2. Birley MH, Mutero CM, Turner IF, et al. The effectiveness of mosquito coils containing esbiothrin under laboratory and field conditions. Ann Trop Med Parasitol. 1987;81(2):163-171.

3. Mosha FW, Njau RJ, Alfred J. Efficacity of esbiothrin mosquito coils at community level in northern Tanzania. Med Vet Ent. 1992;6(1):44-46.

4. Coene J, Nguimbi NP, Mulumba MP. Wéry M. Ineffectiveness of mosquito coils in Kinshasa, Zaire. Trans $R$ Soc Trop Med Hyg. 1989;83(4):568-569.

5. Manga L, Robert V, Carnevale P. Efficacité des serpentins et des diffuseurs en plaquettes dans la protection contre les vecteurs du paludisme au Cameroun. Cahier Santé. 1995;5(2):85-88.
6. OECD. Test No. 436: Acute Inhalation Toxicity-Acute Toxic Class Method. USA: OECD Publishing; 2009. p. 1-27.

7. OECD. Test No. 402: Acute Dermal Toxicity. USA: OECD Publishing; 1987.

8. OECD. Test No. 404: Acute Dermal Irritation/Corrosion. USA; OECD Publishing; 2015.

9. EPA. Atlas of Dermal Lesions. USA: United States Environmental Protection Agency, Office of Pesticides and Toxic Substances; 1990.

10. OECD. Test No. 423: Acute Oral toxicity - Acute Toxic Class Method. USA: OECD Publishing; 2002.

11. Krieger RI, Dinoff MT, Xiaofei Z. Octachlorodipropyl Ether (S-2) Mosquito Coils Are Inadequately Studied for Residential Use in Asia and Illegal in the United States. Environmental Health Perspectives. 2003;111(12):1439-1442.

12. Liu WK, Sun SE. Ultrastructural changes of tracheal epithelium and alveolar macrophages of rats exposed to mosquito coil smoke. Toxicol Lett. 1988;41(2):145-147.

13. Comité de coordination de toxicovigilance. Expositions aux spirales fumigènes anti-moustiques enregistrées dans la BNCI: Analyse des données des Centres antipoison et de toxicovigilance. 2009.

14. Chen SC, Wong RH, Shiu LJ, et al. Exposure to mosquito coil smoke may be a risk factor for lung cancer in Taiwan. J Epidemiol. 2008;8(1):19-25. 